\title{
Knowing when Disagreements are Deep
}

\author{
David M. Adams \\ California State Polytechnic \\ University, Pomona
}

\begin{abstract}
Reasoned disagreement is a pervasive feature of public life, and the persistence of disagreement is sometimes troublesome, reflecting the need to make difficult decisions. Fogelin suggests that parties to a deep disagreement should abandon reason and switch to non-rational persuasion. But how are the parties to know when (if ever) to make such a switch? I argue that Fogelin's analysis doesn't clearly address this question, and that disputes arising in areas like medical decision making are such that the parties to them have reasons to act as if they can be rationally resolved even if they are deep. Fogelin's analysis is thus of limited value as regards the practical moral demand of addressing concrete moral dilemmas.
\end{abstract}

Résumé: Des désaccords sont fréquents dans la vie publique et leur persistance engendre parfois des ennuis et un besoin de prendre des décisions difficiles. Fogelin suggère que les parties en désaccord devraient abandonner la raison et concentrer plutôt sur la persuasion non rationnelle. Mais comment sauraient-ils quand (si jamais) changer d'approche ? J'avance que l'analyse de Fogelin n'adresse pas clairement cette question et le fait que les parties en désaccord dans des domaines telle que la médicine ont raison d'agir comme s'ils pouvaient rationnellement résoudre leurs désaccords, même si ceux-ci sont profonds. L'analyse de Fogelin offre donc une aide limitée pour résoudre en pratique des dilemmes moraux concrets.

Keywords: : Fogelin, deep disagreement, bioethics, Schiavo, artificial nutrition, consensus

\section{Introduction}

Reasoned disagreement is a pervasive feature of public life. Lawyers and judges debate the proper interpretation of a law; scientists argue over the best theory to account for observed data; educators disagree over how best to structure a curriculum; literary theorists divide over the correctness of a certain interpretation of a text; theologians and philosophers present and defend sharply opposing views on issues such as the existence of God and the immortality of the soul. And people from all manner of backgrounds argue for what are sometimes strongly contested positions on a whole variety of moral problems. Despite sometimes vigorous discussion, many of these disagreements remain unresolved. For some of these issues the lack of consensus causes most people no great concern (think, for example, of the metaphysical problem of the freedom of the will). Yet in other cases the persistence of disagreement can be greatly troubling, reflecting the pressing urgency that a resolution be found and a 
decision made: Should "creation science" be part of a high school curriculum? Should capital punishment be prohibited as unconstitutional? Should competent adults be permitted a "right to die"?

But what if it is possible for some disagreements to have a logical structure that entirely precludes rational resolution? This is the alarming possibility raised by Robert Fogelin in "The Logic of Deep Disagreements" (1985). Fogelin argues that deep disagreements are ones in which the disputing parties lack a "normal" background context of shared standards and beliefs, and are instead confronted with a collision of competing sets of belief, incapable of being disentangled through rational argumentation. Fogelin's analysis of why some disputes are not amenable to reasoned resolution is richly suggestive of questions for further philosophical work. In this brief paper I pursue only one of these: What is the practical salience of Fogelin's picture of deep disagreement for those who are parties to actual and persistent disputes? To afford some focus on this question, and since I work both as a philosopher and as a clinical bioethicist in a large community medical center, I shall draw upon familiar and difficult disputes in clinical bioethics to test and assess some of Fogelin's key claims. More specifically, I shall use the recent and highly-publicized case of Terri Schiavo as a lens through which to think about the import of Fogelin's account of deep moral disagreement.

At age 26, Schiavo suffered from severe brain damage due to lack of oxygen after her heart stopped (for reasons that are still not clear). Her husband waged a protracted and very public battle with her parents to remove the surgically implanted feeding tube that for many years sustained her body, insisting that he was simply following what he believed to be her wishes. While its notoriety might suggest that the Schiavo case was in some ways anomalous, the fact is that conflicts in the clinical setting over how best to care for the seriously ill are common and reflect both the continuing development of biomedical technology as well as the clash of widely divergent views regarding how best to use such tools. Complex decisions-for example, whether to continue the use of a ventilator to support respiration or to discontinue hemodialysis in patients with end-stage renal failure, whether to move a patient to "comfort care" or how best to interpret her advance health care directive-are a familiar part of the terrain in every health care institution, and frequently pit patients or their surrogates against each other or their physicians and nurses.

The idea that there could be Fogelin-type deep disagreements in the field of biomedical ethics is disconcerting because the widely accepted response to coping with such dilemmas in the clinical setting has been to invoke procedures for seeking and reaching agreement-for doing, that is, precisely what Fogelin's diagnosis of persistently deep disagreement would say is impossible. Health care organizations have almost uniformly adopted a model of health care ethics consultation, typically conducted by an institutional "ethics committee," as a vehicle for providing guidance and counsel to those involved in disputes regarding clinical care. According to the widely influential report of the American Society for Bioethics and Humanities and 
its predecessor organizations, Core Competencies for Health Care Ethics Consultations (1998), ${ }^{1}$ health care ethics consultation is to aim at bringing about a "consensus among involved parties" described by a range of "morally acceptable options" within the context of a particular clinical case. Health care ethics consultants are to assist in "the building of morally acceptable shared commitments" bounded by "societal values, law, and institutional policy." But if Fogelin's diagnosis of disagreements that are genuinely deep accurately describes the logic of bioethical disputes, the hope of reaching consensus through reasoned argument is illusory. If disagreements typical of the kind that arose in the Schiavo case can correctly be described as deep, then to urge family members, physicians, and those who sit on ethics committees to work toward consensus in dealing with difficult moral questions is to commend to them a futile task. As we shall see, Fogelin's analysis would have it that instead of pursuing rational, argumentative discourse the parties to such futile debates ought frankly and openly to resort to non-rational persuasion in order to put an end to their differences.

Fogelin's central claim seems to be that parties to a dispute ought to attempt to resolve their differences through collective rational deliberation unless their disagreement is deep, in which case they should give up on reason and switch to the use of persuasive tactics. The simple question I want briefly to investigate is: How are the parties to know when (if ever) to make that switch? My claim will be that Fogelin's analysis of deep disagreement doesn't clearly address this question, but that the nature of many persistent disputes, especially the moral disagreements that arise in such disciplines as modern medicine, are such that the parties to them have strong reasons to commit to the idea that they can be rationally resolved in spite of the possibility that such disagreements might ultimately turn out to be deep in Fogelin's sense. Thus, while theoretically of interest, Fogelin's analysis of the structure of deep disagreement is of limited value as concerns the practical moral realities of addressing concerted dilemmas in areas such as bioethics.

I shall first reconstruct and clarify Fogelin's remarks on the nature of deep disagreement and then turn to the relevance of that account to the problem of knowing when a disagreement is deep, and the limited role of Fogelin's analysis of the structure of deep disagreement in practical moral deliberation.

\section{The Analysis of Deep Disagreement}

Though perhaps not explicitly so framed, Fogelin's underlying ambition in "The Logic of Deep Disagreement" is to conduct a kind of Kantian investigation into the conditions of the possibility of argumentative discourse: What are the conditions that make possible argumentative exchanges of the typical sort that Fogelin discusses? Fogelin's central conclusion is that argumentative discourse necessarily occurs against a background of broadly shared beliefs and commitments, including collectively understood procedures for the resolution of disagreements (p. 3). These widely shared beliefs form the logical scaffolding upon which the reasons 
advanced in particular disputes are mounted and against which their salience and probity as relevant depends. To take an example from the clinical setting, imagine that two physicians are discussing a particular patient. "I removed him from the ventilator," says one. "Why?" "Because he is brain dead," replies the first. For this reply to constitute a satisfactory response to the query made, the exchange must have taken place against the backdrop of a complicated set of understandings about, e.g., what ventilators do, what the removal of a ventilator will cause, what constitutes brain death and the procedures and tests for confirming it, what makes brain death an irreversible state, why the death of brains matters in the way that (e.g.) the death of an appendix does not, and about the relevance of the state of brain death to the propriety of removing a ventilator. Fogelin's point just is that such ordinary exchanges would not be possible without the "normal" context of these shared understandings and standards. These background beliefs are already accepted implicitly by the disputants and thus available to be invoked, along with the professed reasons, to support a particular conclusion. As such, the shared context that makes argumentative discourse possible constitutes a set of joint epistemic standards to which the parties can appeal. In this way, argumentative exchanges that assume such a background of underlying agreement occur within a "normal argumentative context" (p. 4).

But what if the shared beliefs characteristic of normal discourse are absent? Deep disagreements reflect an absence of a shared background of beliefs against which the proffered reasons can be expected to secure reasoned assent. Such disagreements occur in the absence of a shared background of assumptions where a clash of two or more sets of mutually supporting beliefs, each resting on distinct "framework propositions" or "forms of life" is revealed (p. 5). These framework propositions are argumentatively basic, such that they are immune to revision by appeal to the facts (p. 5). Fogelin himself suggests that contentious disputes in bioethics (e.g., the abortion debate) are deep in just this way. Those opposed to abortion (or to the use of embryonic stem cells or to the withdrawal of artificial support from comatose individuals) reason from one or another fundamental claim (e.g., the "sanctity of life") that either is wholly rejected by their opponents, or is invested with an entirely distinct meaning (p. 5). Deep disagreements are ones in which none of the contending parties are able to advance reasons as part of an argument that would compel their opponent to accept their position, thereby securing reasoned assent. Fogelin states that in the face of persistent disagreement "the way to put the debate on a rational basis is to surface ... background propositions and then discuss them directly"(p. 5). But, he observes, this won't work if the disagreement is deep. This is the "abnormal" context in which deep disagreement can arise.

It is worth pausing to note several things here before proceeding further. First off, many disagreements - factual and moral-are the products of lack of relevant information, factual errors, mistakes in reasoning, or other such failures of deliberative 
rationality. (Recall Fogelin's discussion of disputants who are "dense" or "pigheaded" (pp. 4-5).) But the presence of these deficiencies does not show that a disagreement is deep. A deep disagreement is (presumably) one that persists (or would persist) even if the parties were fully rational, completely informed of the relevant facts, and possessed of sufficient time and ability to deliberate fully.

On a more general level, it has to be said that Fogelin is not always clear in his explanation of what is required of "normal" argumentative discourse. He asserts several times that normal discourse assumes "a context of broadly shared beliefs and preferences" (p. 3); at other points, however, he says that, minimally, normal discourse must be such that there "exist shared procedures for resolving disagreements" (p. 3). It seems to be his considered view that normal argumentative discourse typically includes both substantive beliefs that are shared (e.g., beliefs about the functioning of the brain and central nervous system) as well as shared procedures for resolving disagreements (e.g., accepted tests to verify lack of brain function). To see what Fogelin is claiming here, suppose that a physician and his colleague disagree on the substantive question of whether a particular patient has suffered brain death. The context of this disagreement is not abnormal-and so the disagreement is not deep-just so long as there are established criteria and specific confirmatory tests for brain death that constitute the accepted standard of practice with regard to ascertaining death on neurological grounds, criteria that allow the doctor and his colleague to settle the question of brain death in the particular case that concerns them. The existence of agreed upon procedures for what counts as evidence of brain death ensures that this disagreement is not deep. Put otherwise, lack of agreement on substantive beliefs (whatever they may be) is not sufficient to transform garden-variety divisions of opinion into deep disagreements - that only occurs when the parties cannot appeal to any standard, criterion, or test to which they are both committed and with which they can set about to resolve their differences. By contrast, imagine that a "pro-life" physician and a "pro-choice" physician are debating whether a first-trimester abortion for reasons other than preserving the life of the mother is morally permissible. Suppose that the first physician's beliefs are grounded in (say) the conviction that the fetus, as a person with rights, begins to exist from the point of conception; the second physician entirely rejects that judgment. Taken together, these basic convictions, each of which supports a set of further beliefs, are straightforwardly inconsistent. Presuming that there exists no decision-procedure or other method for resolving this inconsistency, the disagreement between the two disputants is deep.

One last feature to note about Fogelin's account of deep disagreement is this: Fogelin claims that deep disagreements are ones in which sharp differences persist even when normal sources of discord have been addressed and resolved (p. 5). But this fact alone cannot describe a sufficient condition for a disagreement being deep, since a dispute can be practically speaking irresolvable yet not intractable. Consider, for example, the long-standing controversy over who really killed President 
John Kennedy. This dispute may be incapable of being settled, not due to a failure of deliberative rationality or lack of agreement upon what types of information would settle the dispute, but because of lack of access to the relevant facts. Here we know what kinds of evidence would count, perhaps even decisively, in favor of one or another rival hypothesis about who killed Kennedy. The passage of time and paucity of remaining physical or other forms of evidence, however, simply does not afford sufficient data to isolate the correct explanation. In such a context the disagreement cannot be settled. But Fogelin makes it clear that deep disagreements must be ones in which the very conditions that make argumentative resolution of a debate possible simply do not exist (p. 5).

\section{The Schiavo Case and Deep Disagreement ${ }^{2}$}

Are moral disagreements of the sort raised in the Schiavo case deep? Is bioethical discourse regarding such cases necessarily abnormal? We can best approach these questions by setting out some of the issues raised in that case and reconstructing, at least in sketchy form, the kinds of claims made to support the opposing views taken on those issues.

Terri Schiavo's case turned on numerous disagreements regarding, for example, what she would have wanted her loved ones to do for her, whether her husband ought to have been her surrogate decision maker, whether she could have been rehabilitated, the precise nature of her neurological condition, and (most controversially) whether it is morally permissible to remove a surgically implanted feeding tube from a patient who will die without it. Conflicting accounts were given by Schiavo's husband, Michael, and by her parents and their supporters of how Schiavo herself would have directed her care had she been able to do so. Michael contended that he had held conversations with his wife before her injury in which she had stated she would not wish to be kept alive on artificial support with such a grim prognosis; the parents insisted that Mrs. Schiavo had never expressed such views to anyone and that her husband never mentioned his wife's wishes until some years after her accident. They also pointed out that her Catholic upbringing would have inclined her to the Church's position on the provision of artificial nutrition-namely, that it may not permissibly be foregone. Others disputed this last claim, observing that Schiavo had left the church many years before her accident.

Does the discordance of views over what Schiavo would herself have wanted constitute a deep disagreement? On balance, I do not think that it does. To begin with, it was never disputed by the warring parties that Schiavo's own considered judgments regarding the use of artificial supportive interventions should be respected if they could be discerned. Nor was it apparent that the parties disagreed as to the kinds of procedures that could generally be expected to yield evidence of an individual's considered views. (One procedure commonly used, though not by Schiavo herself, is the preparation of a written advance health care directive, in which one's convictions concerning the use of supportive interventions can be spelled out.) Moreover, it is 
apparent that, because Schiavo did not execute any written set of instructions, it may in fact not be possible to know her wishes clearly and convincingly. On Fogelin's view, then, this disagreement seems much like that over the death of President Kennedy: it is not necessarily deep, even though it is very likely practically irresolvable.

Perhaps a more plausible candidate for a deep disagreement in the Schiavo case concerns the precise nature of her neurological condition: Was she in a "persistent vegetative state" (PVS), as her husband and some of her doctors contended? Or was she in a "minimally conscious state" (MCS), as maintained by her parents? (A patient in a PVS is entirely and permanently unresponsive to any stimuli; those in an MCS do possess some degree of awareness, albeit transient.) Did Schiavo have any degree of conscious awareness of herself and her surroundings? Were her facial expressions and guttural utterances the result of involuntary movements or attempts at meaningful responses and the conscious expression of pain and discomfort? Opinions differed sharply on these (related) questions, and remained so despite the findings of an autopsy, issued several months after Schiavo's death. The medical examiner found that "there was nothing in the autopsy inconsistent with persistent vegetative state," and that Schiavo's brain "showed marked global anoxic-ischemic encephalopathy resulting in massive cerebral atrophy" (Grady, 2005, p.5); yet Schiavo's parents pointed out that the examiner had found her to be "brain-injured, not brain dead" and that she had a strong heart (Hopfensperger, 2005, B1).

Unlike our earlier case involving determination of brain death, this nest of disputes regarding Schiavo's condition appears to have reflected not only a lack of any agreement on how precisely to characterize her neurological status, but also a deeper lack of consensus on what might constitute adequate procedures for determining whether, for any brain-injured patient, she is in a PVS or an MCS. In other words, there was here a lack of agreement both with respect to substantive beliefs (Can she feel pain?) and also with regard to procedural standards (How can we settle whether she is feeling pain?). In this way, the division over Schiavo's neurological status looks like a deep disagreement, and thus not one amenable to a reasoned argumentative resolution. Yet the inference to this conclusion could be challenged. For example, future developments in neuroscience could make it possible to make increasingly fine-grained assessments of patients with brain injuries, so that the precise boundaries between PVS and other neurological syndromes or states might be more sharply delineated and a uniformly accepted standard thereby worked out. This reply of course assumes something Fogelin may not be willing to grant: namely, that disagreements are not deep as long as it is possible for the disputants to develop procedures for resolving their dispute even though they have yet to do so.

Certainly the most potentiaily contentious disagreement raised by the Schiavo case concerns the moral status of artificially-provided nutrition. Supporters of Schiavo's husband argued (in terminology made familiar by the Catholic church) that 
artificial feeding tubes should be considered "extraordinary" means of life support and thus not morally required if the benefit provided is outweighed by the burdens (suffering and indignity) imposed. Opponents of this view (including the Church itself) maintained that the provision of food is a response to a basic human need and ought not to be regarded as optional treatment. To remove a gastrostomy tube, according to the view of Schiavo's parents, is just to starve the patient to death. Here the contending views appear to be premised on basic convictions (Fogelin's "framework propositions") each of which is the denial of the other:

(1) Removing artificial nutrition and hydration is always an impermissible act of starvation.

and

(2) Removing artificial nutrition and hydration is at least sometimes a permissible act of compassion and respect for patient autonomy.

These claims are logically incompatible. And something very much like them seems to have animated the opposing factions in the sometimes ugly "culture war" that erupted throughout America as Schiavo neared the end of her life. ${ }^{3}$ It seems safe to conclude that the disagreement reflected in the juxtaposition of these claims is at least consistent with the disagreement being deep.

\section{Agreement, Consensus, and Non-Rational Persuasion}

Let us suppose, then, that at least some of the disputes raised by the Schiavo case are possibly deep in just Fogelin's sense. What ought to be the practical upshot of this fact? How ought the fact that a disagreement might turn out to be deep affect the conduct of the disputants themselves and those, such as members of hospital ethics committees, who are charged with the responsibility of assisting in the resolution of such disputes?

Fogelin writes as if to say that, practically speaking, the import of the fact that a disagreement is deep is that the involved parties not further waste their efforts on rational argumentation. Quoting with approval Wittgenstein's remark that "at the end of reasons comes persuasion," (p. 6) Fogelin asks: Where the discourse is abnormal and we have to fall back upon persuasion, "what's so bad about using these [persuasive] techniques right from the start?" (p. 6). Fogelin's view seems to be that deep disagreements are not uncommon but nonetheless not particularly worrisome either, since one can always resort to non-rational means of persuasion in order to move opposing parties to a place of agreement. Fogelin implies that disagreements incapable of resolution through rational argumentation do not necessarily constitute a complete practical impasse, since the relevant beliefs can be changed without rational argumentation through the use of non-rational persuasion. Fogelin is almost entirely silent on what such non-rational techniques might include, though he does cite Wittgenstein's parenthetical remark "Think what happens when missionaries convert natives" (p. 6). Presumably, then, we could attempt to bring it about that those with contesting views are moved to agree, not "on the merits," 
as it were, but by virtue of (say) appeals to self-interest or fear or empathy. Appeals to authority or emotion, indoctrination techniques, and other rhetorical ploys and devices could all conceivably fall into the category of non-rational efforts to bring about or induce acceptance of a belief.

So, where the discourse is abnormal, Fogelin's recommendation is to abandon rational deliberation in favor of these techniques of persuasion. In the context of bioethical decision-making, of course, this recommendation is plainly at odds with the accepted model for seeking to resolve disputes like those that arose in the Schiavo case. That model, as explained earlier, is bottomed on the attempt to resolve such disagreements through efforts at reaching consensus. To pursue this point further, it surely would not be sufficient on the consensus model simply to bring it about by non-rational means that those with previously discordant views now hold opinions that converge, such that there is unanimity of opinion in a difficult case. In that sense, 'consensus' would merely be the name of an outcome: The ethics committee took a poll and (perhaps surprisingly) everyone voted the same way. But mere convergence of opinion or belief upon a particular conclusion is not sufficient for an agreement to count as an instance of "facilitated consensus"; the fact that the warring family members happen to arrive at the same moral judgment in a particular case would not be sufficient grounds for claiming that a consensus decision had been reached. The ASBH Report's discussion of "facilitating consensus" indicates that it means to require more than merely a discovery that everyone gives assent to a given proposition, regardless of how that mutual assent comes about. "Consensus" is not simply the name of an outcome but an achievement--something produced by a form of collective moral reflection and deliberation, a process of being mutually convinced by reasons. This emphasizes the way in which the moral authority of an agreement depends in some way upon how it was developed.

Non-rational means of persuasion could conceivably be used to move the parties involved in a Schiavo-type dispute to settle their differences with the negotiation of a compromise, motivated by (say) the skillful deployment of rhetorical tactics. But the facilitation of consensus ought not, I think it is clear, to be viewed in this way. Suppose a physician wants her patient to undergo both a tracheostomy and the placement of a surgically implanted feeding tube; but the family rejects both. Imagine further that the ethics consultation in this case had sought, through non-rational appeals to self-interest or fear or what have you, to bring the contending parties to accept a compromise: the tracheostomy would be performed, but not the feeding tube insertion, so that each side would "come away from the table" with a concession. Why would it be wrong to produce agreement in this way by "splitting the difference" between rival views? The answer, I think, must have something to do with the belief that the moral goal of resolving bioethical disputes is to identify that course of action deemed somehow to be in the best interests of the patient. Striking a bargain or reaching a compromise between two opponents may meet their need to resolve their differences and move on, but the focus of ethics consultation is supposed to be the patient's well being, not those of the people around the table. To make 
treatment decisions in this way based upon what will satisfy the rivals rather than what is in the best interests of the patient seems prima facie to exhibit a moral failing in the consultative process.

The use of non-rational forms of persuasion to produce agreement, urged upon us by Fogelin's analysis, is therefore problematic, both procedurally and substantively, in attempts to settle serious and difficult bioethical problems. Procedurally, the goal in resolving bioethical disagreements, at least in the clinical setting, is not simply agreement secured by whatever (non-rational) means, but agreement that constitutes a genuine consensus - that is, agreement as the outcome of reasoned, collective deliberation. The resort to non-rational forms of persuasion, to the extent that they undercut the very possibility of such deliberation, is incompatible with the generally accepted process for coping with bioethical dilemmas. Moreover, the process whereby parties to a bioethical dispute reach consensus may properly be constrained substantively by moral norms (for example, the principle that medical decisions must reflect the patient's best interests) the salience of which cannot be captured by reliance upon non-rational manipulation of the parties to a disagreement.

\section{Knowing When a Disagreement is Deep}

Fogelin's recommendation that those confronted with a deep disagreement abandon rational argumentative discourse faces a more significant hurdle than its inconsistency with the idea of collective moral decision making. For to forsake the pursuit of reasons makes sense as a recommendation only on the assumption that the disputants not only are locked in a deep disagreement, such that further efforts at rational deliberation would prove unavailing, but that they know they are. Here we come to a point crucial to the relevance of Fogelin's analysis to practical reasoning. Just how are we to know when the conditions that make argument possible are incapable of being satisfied? For any given case, in what way are we to know that we have correctly identified the disagreement at hand as deep or (which comes to the same thing) the discourse as "abnormal"? This question highlights an important feature of Fogelin's analysis. It purports to set out the logical features of a deep disagreement, but it does not specify any epistemic criteria sufficient to ground the belief that a given disagreement is in fact deep. More generally, Fogelin's analysis tells us what counts as a deep disagreement in the sense of limning its logical structure. But it doesn't tell us how to establish in a given case whether a particular dispute is amenable to rational resolution.

How, then, can we tell when a disagreement is deep? As we have already seen, the fact that a persistent disagreement appears to the parties to be deep is no guarantee that it is. The dispute discussed above between those who support and those who reject the permissibility of removing artificial nutrition from a brain-damaged patient may seem to be irresolvable due to a lack of mutually accepted beliefs. But again the 
appearance of a deep disagreement here might turn out to be deceptive. Recall the two claims that look to be a stake in the Schiavo case:

(1) Removing artificial nutrition and hydration is always an impermissible act of starvation.

And

(2) Removing artificial nutrition and hydration is at least sometimes a permissible act of compassion and respect for patient autonomy.

Suppose now that discussion with the advocates of (1) and (2) reveals that they do in fact share a commitment to some third claim, say:

(3) Disagreements over the use of artificial supportive medical interventions (such as tube feedings) should be settled by appeal to the best interests of the patient.

According to Fogelin's analysis, the fact that proponents of (1) and (2) know that they share a commitment to (3), which purports to set out a procedure for resolving certain kinds of disagreement, seems sufficient to assure them (and us) that they are still operating within the realm of normal discourse.

Confronted with this last contention, Fogelin might well object that if the parties on opposing sides of the debate over artificial nutrition can still arrive at opposing positions even in the face of a shared acceptance of (3), then it seems plain that the appeal to such an abstract procedural principle is doing no real work. Put another way, the mere fact that the disputants accept (3) is not sufficient to transform the context of their disagreement into normal discourse. For that to occur such shared beliefs must be capable of doing real argumentative work; it must be possible, that is, for the disputants to be brought argumentatively to resolve their disagreement over the permissibility of removing artificial nutrition by appeal to something like (3). But if that is in fact not possible, then mutual acceptance of (3) is logically compatib!e with the state of affairs in which supporters of (1) and of (2) deeply disagree.

But Fogelin's rejoinder here misses the point of the epistemic worry raised by his recommendation to abandon rational argumentative discourse when disagreements are deep. For the problem is how the contestants are to know that none of the beliefs, commitments, or procedures to which they mutually assent could form the basis of a reasoned resolution of their disagreement. Presumably, even people sharply divided over the moral status of artificial nutrition and hydration nonetheless share a multitude of factual and moral beliefs. But whether the parties are operating outside the scope of normal discourse, such that whatever beliefs they share are incapable of doing the work necessary to resolve their dispute, is precisely what the parties themselves need to know before they abandon their efforts to reason from shared beliefs in principles like (3) to a resolution of their differences. As a practical matter, it is not clear what could count on Fogelin's view as a discovery by the disputing parties that a disagreement is deep, since it could not confidently be concluded that the gulf separating proponents of (1) and (2) is unbridgeably deep unless all possible beliefs and commitments, substantive and procedural, for bridging 
that gap are rejected by one or both of the parties. More generally, the logic of deep disagreement makes it impossible to specify a priori conditions such that, for any disagreement, satisfaction of just those conditions would be necessary and sufficient epistemically to conclude that the disagreement is deep. The only way for the parties to know whether such a state of affairs obtains is by continuing to work through an attempt at rational discourse, and this because the question of whether a given disagreement is deep can only be settled by exhausting the possible resources of normal discourse. All of this means that the only way for the parties to establish that their disagreement is deep is to reject the very path of non-rational persuasion recommended by Fogelin and concentrate instead on their collective efforts at mutual persuasion by reasons. The only way, in other words, to come to know whether discourse is normal is to proceed as if it is.

To this, it may be asked why the disputing parties in the case of artificial feeding tubes couldn't reach a point where it would be apparent to them that they have exhausted the resources of normal discourse. The answer, I think, is that while certainly this is a logically possible result of collective deliberation, it is not a practically attainable end point. Problems in clinical bioethics cannot await the kind of systematic and comprehensive examination of the logical structure of systems of belief that would be required to demonstrate that "normal" conversation is no longer possible on a particular question. Indeed, a large part of what makes most bioethical dilemmas in clinical care so wrenching for those involved is the necessity to make decisions under conditions of uncertainty, and this because all of the possible courses of action open to a physician or family in such a case (for example, to start a patient on a ventilator now or to wait to do so) impose costsemotional, physical, and financial. Hence the moral pressure to make a decision and accept the consequences, whatever they may be. Under these circumstances, delaying the effort to arrive at a reasoned decision on the grounds that the disagreement might be one that is actually deep is itself a decision to impose costs and may be indefensible morally if those costs are greater than would be created by abandoning rational discourse and resorting to non-rational tactics to end the matter. And as we have seen, this claim is reinforced by the conclusion of the previous section that the widely-accepted bioethical goal of consensus presupposes a commitment to persuasion through rational, argumentative discourse.

\section{Conclusion}

If Fogelin is right, then it is possible for people to disagree deeply on a whole variety of issues, including the bioethical debates illustrated so tragically by the case of Terri Schiavo. But the prospect that a clash of opposing views might be so deep as to be rationally irresolvable can, I think, have little practical effect on the efforts of disputants who, quite properly, continue to proffer reasons and develop arguments in the hope that they may move each other to a mutually acceptable position on the problem that divides them. 


\section{Notes}

'A summary of the ASBH Report appeared in Aulisio et al. (2000) and Aulisio et al. (2003).

${ }^{2}$ For history and analysis of the Schiavo case, see In Re: Guardianship of Schiavo 780 So. 2d 176 (2001); In Re: Guardianship of Schiavo 792 So. 2d 551 (2001); and Annas (2005).

${ }^{3}$ See Annas (2005).

\section{References}

American Society for Bioethics and Humanities. 1998. Core Competencies for Health Care Ethics Consultations. Glenville, IL.

Annas, George. 2005. "Culture of Life' Politics at the Bedside: The Case of Terri Schiavo," New England Journal of Medicine, Vol. 352, Apr. 21: 1710-1715.

Aulisio, Mark P., et al. 2000. "Health Care Ethics Consultation: Nature, Goals, and Competencies," Annals of Internal Medicine, Vol. 133, No. 1, July: 59-69.

Aulisio, Mark P., et al. 2003. Ethics Consultation: From Theory to Practice. Baltimore: The Johns Hopkins University Press.

Fogelin, Robert: 1985 “The Logic of Deep Disagreements," Informal Logic, 7.1: 1-8. Reprinted in Informal Logic, 25.1 (this issue): 3-11.

Grady, Denise. 2005. "The Hard Facts Behind A Heartbreaking Case," New York Times, June 19, Section 4.

Hopfensperger, Jean. 2005. "Schiavo Family Unswayed by Autopsy's Conclusions," Minneapolis Star Tribune, June 17.

David M. Adams

Department of Philosophy California State Polytechnic University, Pomona Pomona, CA 91768

dmadams@csupomona.edu 